\title{
Facilitation effects of cueing techniques in two Sesotho speakers with anomia
}

Brent Archer, Nicole Müller and Claire Penn

\author{
Linköping University Post Print
}

Tweet

N.B.: When citing this work, cite the original article.

Original Publication:

Brent Archer, Nicole Müller and Claire Penn, Facilitation effects of cueing techniques in two Sesotho speakers with anomia, 2016, Speech, Language and Hearing,, , .

http://dx.doi.org/10.1080/2050571X.2016.1155817

Copyright:

http://taylorandfrancis.com/journals/

Postprint available at: Linköping University Electronic Press

http://urn.kb.se/resolve?urn=urn:nbn:se:liu:diva-128689 
Archer, B., Müller, N. and Penn, C. (2016). Facilitation effects of cueing techniques in two Sesotho speakers with anomia. Speech, Language and Hearing, 19, 140-153.

Facilitation effects of cueing techniques in two Sesotho speakers with anomia

\author{
Brent Ernest Archer ${ }^{1}$, Nicole Müller ${ }^{2}$, Claire Penn ${ }^{3}$
}

${ }^{1}$ University of Louisiana at Lafayette, PO Box 43170, Lafayette, LA 70504-3170, USA,

${ }^{2}$ Clinical and Experimental Medicine - Speech \& Language Pathology, University of

Linköping, Sweden, ${ }^{3}$ University of the Witwatersrand, Johannesburg, 1 Jan Smuts Avenue,

Braamfontein, Gauteng 2000, South Africa

Correspondence to:

Brent Ernest Archer,

University of Louisiana at Lafayette,

200 East Taft Street, 70501,

USA.

E-mail: be.arch.za@gmail.com 
Archer, B., Müller, N. and Penn, C. (2016). Facilitation effects of cueing techniques in two Sesotho speakers with anomia. Speech, Language and Hearing, 19, 140-153.

\section{Abstract}

Aphasiologists developing treatments for anomia should closely align therapy methods with the typological and morphological characteristics of the language in question. The lead author initiated this study to develop more defensible interventions for speakers of Sesotho, a South African language. Prefix-based cueing (our alternative name for initial phoneme cueing that describes these cues in Sesotho-oriented terms) was compared to a novel technique, root-based cueing (RBC). While prefix-based cues are described in the literature, we hypothesized root-based cues would be more appropriate in this context since they were thought to be more consonant with the linguistic parameters of Sesotho. Two speakers with aphasia, who demonstrated significant anomic symptoms, served as participants. We used a multiple-baseline, single case study design. Two 144-item word lists were developed with every item represented by a photograph. Each of the two word lists was associated with one of the two cueing techniques investigated. After baseline measurements were obtained, each participant attended eight facilitation sessions for each cueing condition, resulting in eight data points per condition and participant. For both participants, RBC resulted in greater naming performance than cueing by means of initial phonemes. Our explanation of these results is based on the Interactive Lexical Network model of lexical access; root-based cues may be more effective because they more efficiently constrain the number of lemmas activated after a cue is provided. We argue that a confluence of factors (word-retrieval processes and the character of Sesotho morphosyntax) gave rise to the noted differences in naming facilitation.

Keywords: Aphasia, Anomia, Interactive network model, Sesotho, Facilitation 
Archer, B., Müller, N. and Penn, C. (2016). Facilitation effects of cueing techniques in two Sesotho speakers with anomia. Speech, Language and Hearing, 19, 140-153.

\section{Introduction}

The aim of this case study investigation was to compare the facilitatory effects of cueing techniques for improving naming performance in two Sesotho speakers with anomia. Two cueing techniques were selected: initial phoneme cueing and a novel technique based on the provision of the first sound of an uninflected noun root. We hypothesized that the novel technique would prove more effective since it is informed by an appreciation of the morphosyntax of Sesotho. This view was born out by a statistical analysis of our findings. Treatment programs which feature initial phoneme cues improve naming performance in English speakers with anomic symptoms as evidenced by a number of studies (Abel et al., 2005; Bruce and Howard, 1987; Conroy et al., 2009; Greenwood et al., 2010; Nettleton and Lesser, 1991; Wambaugh et al., 2001). However, aphasia is known to affect different languages differently. For example, Grodzinsky (2000) proposed that people with expressive aphasias who speak +zero morphology languages tend to omit morphemes while similarly impaired speakers of -zero morphology languages tend to erroneously substitute morphemes. (+zero morphology languages license the production of uninflected forms. For example, while English inflects plural nouns, there is no morphological marker used to denote singular forms. -zero morphology languages like Polish require that speakers inflect various classes of words; bare, uninflected stems are illegal in -zero morphology languages.) If certain symptoms of aphasia are language-specific, it is reasonable to ask whether or not certain therapeutic effects are also the product of parameters unique to a given language or language family.

Despite widespread use of initial phoneme cueing by South African clinicians, the lead author found therapy outcomes linked to this technique were of a much smaller magnitude than those described in the literature (Penn and Archer, 2011). An analysis informed by an appreciation of Sesotho's unique traits, specifically its inflectional 
Archer, B., Müller, N. and Penn, C. (2016). Facilitation effects of cueing techniques in two Sesotho speakers with anomia. Speech, Language and Hearing, 19, 140-153.

morphology, provides possible reasons for why initial phoneme cues may not have been appropriate as a therapeutic technique. Sesotho, a Bantu language spoken by about six million people in southern Africa, is typically classified as an agglutinative language (Sejaphala, 2010). In common with other Bantu languages, Sesotho nouns can be divided into a number of noun classes (14 by the best available analysis) (Demuth, 2000). Barring a very small number of exceptions, nounclass membership is semantically arbitrary. Each noun class has its own set of morphological markers, listed in Table 1. These markers are applied with a high degree of regularity (Doke and Mofokeng, 1967). Diminutive, demonstrative, interrogative, possessives, enumerative, and locative morphemes also exist for each noun class (Mokoena, 1998). Similarly, each noun class uses a set of singular/plural prefixes to encode number. For example, lehapu 'watermelon' is a member of the le-/ma- class ('watermelons' mahapu), while moruti 'priest' is a member of the mo-/ba- class ('priests' baruti). Uninflected roots (*hapu, *ruti) are ill formed, and do not occur in spontaneous speech or in dictionaries.

Table 1: Noun classes featured in this study

\begin{tabular}{|l|l|l|l|l|}
\hline Noun class & Singular Example & Gloss & $\begin{array}{l}\text { Plural } \\
\text { Example }\end{array}$ & Gloss \\
\hline mo-/ba- & motho & person & batho & people \\
\hline mo-/me- & mose & dress & mese & dresses \\
\hline le-/ma & letsatsi & sun & matsatsis & suns \\
\hline se-/di- & sefate & tree & difate & trees \\
\hline
\end{tabular}

Since English nouns are never inflected via prefixes, initial phoneme cueing is a straightforward method for providing the targeted external activation needed to overcome word-retrieval difficulties in English. Sesotho, on the other hand, employs noun-initial prefixes (every noun needs a singular/plural marker in order to be well-formed), so an initial phoneme cue may not be as effective at facilitating naming. Other approaches, which align 
Archer, B., Müller, N. and Penn, C. (2016). Facilitation effects of cueing techniques in two Sesotho speakers with anomia. Speech, Language and Hearing, 19, 140-153.

better with the unique parameters of Sesotho, might be more useful. A previous paper describing a pilot investigation (Penn and Archer, 2011) suggested two such Sesotho-oriented techniques (prosodically oriented cues and cues based on the uninflected root) were more appropriate than first phoneme cueing when working with Sesotho speakers. Since Penn and Archer (2011) considered the effects of four types of cues on a small number of stimuli (20), the findings presented at that stage were regarded as preliminary. The current study focuses on only two cueing techniques, and uses a much larger set of stimuli. Moreover, while Penn and Archer (2011) presented insufficient data to support a robust statistical analysis, the current study produced enough data to conduct various procedures and generate more defensible findings. This paper thus extends on and supports the earlier work published by Penn and Archer (2011).

Ideally, practices within speech-language pathology should not only be informed by an appreciation of the uniqueness of each language but also be grounded in theories of normal and impaired language functioning. To this end, aphasiologists often use wellsupported models of normal word retrieval to inform research, such as the Interactive Lexical Network (ILN) ${ }^{1}$ model (Dell et al., 1997).

Under the ILN model, each word that a speaker knows is represented in the mental lexicon as a lemma (Dell and Reich, 1981). Each lemma, in turn, has connections to two layers of features, viz. semantic features and phonological features (Dell and Reich, 1981). According to the ILN model, mental activity occurs at different points in the network, and structures needed to complete word-retrieval tasks act upon and modify the information stream moving between levels (Levelt, 1999). When a speaker is asked to name a picture of a

\footnotetext{
${ }^{1}$ While other models of word retrieval have been developed (for example, WEAVER++) (Levelt and Meyer, 2000) we have chosen to focus on the ILN because it is supported by a substantial amount of empirical research (see Dell et al., 2014 for a review) and because it is widely cited in the aphasiological literature (see Wilshire, 2008, for a review).
} 
Archer, B., Müller, N. and Penn, C. (2016). Facilitation effects of cueing techniques in two Sesotho speakers with anomia. Speech, Language and Hearing, 19, 140-153.

dog, semantic nodes associated with a variety of lemmas become active. There is a substantial semantic overlap between the lemmas for 'dog' and 'wolf'. 'Cat' shares a narrower range of its semantic features with the target word. All of these (and other lemmas) receive 'activation' from semantic nodes, but since the target is 'dog', this lemma receives the most activation. As such, the target lemma is able to send the greatest amount of activation to the phonological nodes implicated in the production of /dng/. This pattern reoccurs at the phonological level; the nodes linked to lemmas semantically related to 'dog' ('wolf', 'cat') all receive a small amount of activation while the nodes associated with 'dog' receive the largest amount of activation. Though activation cascades through the system and many non-target lemmas and nodes receive activation, those structures with the most activation drive the process onward (Dell et al., 1997). Later activation from the phoneme nodes flows to the structures and processes which drive the production of speech sounds (Dell, 1986).

The concept of feedback is crucial for understanding the results of studies of impaired word retrieval. While some authors have argued in favor of unidirectional activation flow at certain levels in the word-retrieval system (for example, Levelt et al., 1999), experimental evidence lends credence to the notion of feedback (Costa et al., 2000). Activation flows 'forward' (semantic nodes-lemma-phonological nodes) and 'backward'. When a lemma or phonological node comes online, it transmits a small amount of activation along the links which cohere it with structures at 'higher' levels. Instead of progressing serially from stage to stage, activation spreads diffusely through the network during word retrieval (Dell et al., 1997). Activation is also thought to decay with the passage of time (Kendall et al., 2013). Dell et al. (2014) use computer models to simulate some errors produced by neurologically intact speakers in terms of an interaction between cascading, feedback, and decay. These factors interact to give rise to noise, or random, off-task activity in the network. Speakers are 
Archer, B., Müller, N. and Penn, C. (2016). Facilitation effects of cueing techniques in two Sesotho speakers with anomia. Speech, Language and Hearing, 19, 140-153.

known to edit their productions to ensure that words uttered actually match the constraints of the task and that phonemes accurately align with semantic features, though how such weeding out of errors occurs is poorly understood (Dell et al., 2014). According to Dell et al. (1999) phonemic, semantic, and mixed paraphasias may occur in everyday speech because noise may, at times, overwhelm the system's editing capabilities.

Several explanations derived from this model have been used to account for wordfinding difficulties in speakers with aphasia. Links between lemmas and the semantic and phonological feature levels are thought to have 'weight' (Dell et al., 1997). The weight of each link corresponds to the amount of activation it is able to transmit. If a word is to be retrieved successfully, the activation flowing from the semantic level to a lemma, from a lemma to the phonological level, and from the phonological level to the speech programming apparatus needs to be sufficient in strength and duration to drive the process (Dell et al., 1999). Low connection weights and/or premature decay result in sub-optimum activation flow, which in turn impairs a speaker's ability to retrieve words (Dell et al., 1999). The effects of low connection weights may be exacerbated in some speakers with aphasia by elevated random activity within the network; neurological damage is thought to increase the amount of noise during word-retrieval tasks, leading to the paraphasias which occur in the output of some people with anomia (Dell et al., 2014).

In summary, a study which compares the facilitatory effects of two techniques for improving naming performance and how common models of word processing can be used to interpret inter-technique differences is of cardinal relevance to therapists in South Africa, since therapy services are almost always dispensed in environments where time and money exist at a premium (Penn and Beecham, 1992). While all therapists endeavor to provide the best, most efficient services possible, this imperative is even more pressing in underresourced contexts (Pascoe et al., 2010). Further, many therapists in other countries will 
Archer, B., Müller, N. and Penn, C. (2016). Facilitation effects of cueing techniques in two Sesotho speakers with anomia. Speech, Language and Hearing, 19, 140-153.

routinely encounter clients who speak languages other than English. A study which compares a technique developed by English-speaking therapists for English-speaking clients to one developed specifically for clients who speak a language radically different from English can inform practice in the complex global village, and help to begin to address the bias towards English and Western European languages in the aphasiological literature noted by Beveridge and Bak (2011).

\section{Methods}

\section{Development and adaptation of resources}

An allied health worker who was a first language speaker of Sesotho was paid and trained to serve as an interpreter in this study. She helped develop the word lists, adapt formal tests into Sesotho, delivered the cues under both facilitation conditions, and collaboratively (in cooperation with the lead researcher) recorded the naming accuracy and error data used for further analysis. (Further details on the adaption and interpretation process are available in Supplementary Materials.)

\section{Participant recruitment and selection}

In order to control for spontaneous recovery, only participants who suffered a stroke more than 1 year before the study started were considered. Both participants were recruited from the adult neurological caseload (consisting of approximately 100 individuals) of a speech-language pathologist (the lead author) employed at a hospital. Participants were asked to discontinue their usual speech-language therapy (including home-based activities) for the duration of the study. 
Archer, B., Müller, N. and Penn, C. (2016). Facilitation effects of cueing techniques in two Sesotho speakers with anomia. Speech, Language and Hearing, 19, 140-153.

\section{Inclusion criteria}

We sought participants whose primary symptom was anomia. Given the severely under-resourced context in which this study was conducted (a rural African hospital) no scanning technology for assessing the site of lesion, such as magnetic resonance imaging (MRI), was available. However, a range of measures and observations were used to ensure that the selected participants were appropriate for this study:

(1) Adapted Sesotho ${ }^{2}$ versions (Archer, 2010) of the main subtests of the Western Aphasia Battery (WAB) (Kertesz, 1982) were used as the primary evaluation tool (see Supplementary Materials - adapted WAB). Only participants who presented with anomic aphasia as defined in theWAB were eligible for inclusion.

(2) An adapted Sesotho version (Archer, 2010) of the Boston Naming Test (Kaplan et al., 1983) (see Supplementary Materials - adapted BNT) was used to verify the presence and severity of anomic symptoms.

(3) Adapted Sesotho versions (Archer, 2010) of relevant subtests of The Psycholinguistic Assessments of Language Processing in Aphasia (PALPA) (Kay et al., 1992) were used in order to further categorize the language deficit (see Supplementary Materials - adapted PALPA).

(4) Clinical observations conducted by the researcher over the course of 6 months during routine speech- language pathology before the study commenced provided insights into each participant's abilities, strengths, and weaknesses.

\footnotetext{
${ }^{2} \mathrm{We}$ are aware of the challenges that arise when altered versions of psychometric tests are used to assess study participants. Crucially, adaptation of a test into another language will compromise the ability of the test to rank a participant relative to the population on which the test was normed. Our intention here was never to compare participants' language abilities to other people with aphasia. Rather, we used the tests primarily to investigate the nature and mechanism of participants' anomic symptoms.
} 
Archer, B., Müller, N. and Penn, C. (2016). Facilitation effects of cueing techniques in two Sesotho speakers with anomia. Speech, Language and Hearing, 19, 140-153.

(5) Clinical conferences were conducted with each participant's physicians and neurologists to confirm the nature of the language disorder.

\section{Language history}

Only participants who were first language speakers of Sesotho were eligible for inclusion. This status was confirmed in a language history interview with the participants and their primary caregivers. This interview included questions on the age at which Sesotho was acquired, the manner in which it was acquired, the current use of Sesotho, and pre-morbid Sesotho proficiency of language and literacy (after Paradis and Libben, 1987).

\section{Exclusion criteria}

Individuals with global aphasia as defined by theWAB (Kertesz, 1982) were excluded, since a minimum ability to understand and participate in experimental tasks was a prerequisite for participation. Moreover, a hearing loss (defined here as a hearing loss associated with a pure tone average of 26 decibels and lower) (Martin, 1994), severe dysarthria/apraxia (as measured using the Robertson Dysarthria Profile) (Robertson and Thomson, 1986), confirmed visual-- perceptual deficits such as hemianopia as evidenced by caregiver and/or medical reports, and a history of developmental speech-language deficits as determined by self-reports or by primary caregiver reports were grounds for exclusion. Since education levels can influence language use and abilities, only participants who had completed high school were included. 
Archer, B., Müller, N. and Penn, C. (2016). Facilitation effects of cueing techniques in two Sesotho speakers with anomia. Speech, Language and Hearing, 19, 140-153.

\section{Participant description}

Two Sesotho speakers with anomia as a sequela of cerebrovascular accidents participated in this study, which commenced in May 2008. The participants in this study are the same as those described in Penn and Archer (2011).

\section{Participant T.}

T. was a right-handed 42-year-old male who suffered a stroke in April of 2007. He enrolled in this study 13 months after having a stroke. T. completed 12 years of formal schooling, with Sesotho being the primary language of instruction. Before his stroke, T. was employed as a security guard and driver for 20 years. He used Afrikaans on a daily basis as part of his job, and was also able to communicate fluently in English.

T. attended once weekly speech-language therapy (provided by the lead author) before the commencement of this study for about 6 months. He resided in the Free State Province of South Africa. He suffered a left-sided CVA and presented with a fluent aphasia. No objective assessments of the locus of his lesion were undertaken but his symptoms (language disorders, decreased processing speed) seemed to indicate a cerebral locus of insult. No significant basal ganglia or cerebellar signs were noted upon examination. Assessment and observational data indicated that T. displayed symptoms of a naming impairment. He obtained a score of 13/60 on a Sesotho-adapted version (Archer, 2010) of the Boston Naming Test (Kaplan et al., 1983). During conversational interaction, T. would often circumlocute or simply omit the target word. He occasionally produced the initial phonemes of words while talking in English, Afrikaans, and Sesotho. A sampling of these circumlocutions and part-word productions is provided in Table 2. T. was able to understand a wide range of complex structures such as non-present tense sentences, passive sentences, 
Archer, B., Müller, N. and Penn, C. (2016). Facilitation effects of cueing techniques in two Sesotho speakers with anomia. Speech, Language and Hearing, 19, 140-153.

sentences featuring multiple embedded clauses, etc. He was also able to produce appropriate speaking turns.

Table 2: Sample part-word productions and circumlocutions produced by participant $\mathrm{T}$.

\begin{tabular}{|l|l|l|}
\hline Target & Translation & Production \\
\hline sefate & tree & "se-...sefa..." \\
\hline tafula & table & "t...ta" \\
\hline bohobe & bread & "boho..." \\
\hline sethunya & gun & "s...sethu..." \\
\hline katiba & hat & "ka..." \\
\hline kgaba & spoon & "used for eating porridge" \\
\hline kgwedi & moon & "in the sky at night" \\
\hline tepu & spider & "lives on a web" \\
\hline pelo & heart & "beating" (gesture: touches chest). \\
\hline tlhapi & fish & $\begin{array}{l}\text { "swims..." (gestures: makes } \\
\text { waving motion with hand, } \\
\text { mimicking fish swimming through sea). }\end{array}$ \\
\hline
\end{tabular}

Table 3 details T.'s scores on Sesotho-adapted versions of the PALPA and the WAB. As can be seen, T. presented with mild deficits across a range of communicative functions. However, during tasks which required decontextualized lexical retrieval (such as confrontation naming), he displayed more obvious signs of dysfunction. The Aphasia Quotient obtained by T. during formal testing is consistent with a diagnosis of anomic aphasia.

Table 3: Test scores for participant $\mathrm{T}$.

\begin{tabular}{|l|l|}
\hline PALPA & \\
\hline Subtest & Score \\
\hline 8. Repetition: Nonwords & $28 / 30$ \\
\hline 8. Repetition: Nonwords reading & $27 / 30$ \\
\hline $\begin{array}{l}\text { 9. Repetition: Imageability and Frequency, high } \\
\text { imageability words only }\end{array}$ & $38 / 40$ \\
\hline 36. Oral Reading: Nonwords & $21 / 24$ \\
\hline 45. Spelling to dictation: Nonwords & $22 / 24$ \\
\hline 47. Spoken Word-Picture Matching & $32 / 40$ \\
\hline 48. Written word- picture matching & $34 / 40$ \\
\hline 53.1 Spoken Picture Naming & $9 / 40$ \\
\hline 53.2 Written Naming & $30 / 40$ \\
\hline
\end{tabular}


Archer, B., Müller, N. and Penn, C. (2016). Facilitation effects of cueing techniques in two Sesotho speakers with anomia. Speech, Language and Hearing, 19, 140-153.

\begin{tabular}{|l|l|}
\hline 53.3 Oral reading & $39 / 40$ \\
\hline 53.4 Repetition & $38 / 40$ \\
\hline 53.5 Written spelling & $35 / 40$ \\
\hline 54. Picture naming. & \\
High frequency & $11 / 20$ \\
Medium frequency & $3 / 20$ \\
Low frequency & $6 / 20$ \\
\hline & \\
\hline WAB & \\
\hline Subtest & Score \\
\hline Spontaneous Speech: Functional Content & 5 \\
\hline Spontaneous Speech: Fluency & 4 \\
\hline Spontaneous Speech Total & 9 \\
\hline Comprehension: yes/no questions. & 60 \\
\hline Comprehension: auditory word recognition & 60 \\
\hline Comprehension: sequential commands & 80 \\
\hline Comprehension Total: (scores divided by 20) & 10 \\
\hline Naming: Object Naming & 18 \\
\hline Naming: Word Fluency & 12 \\
\hline Naming: Sentence Completion & 3 \\
\hline Naming: Responsive Speech & 7 \\
\hline Naming Total: & 4 \\
\hline Repetition: & 10 \\
\hline Aphasia Quotient (AQ): & 66 \\
\hline
\end{tabular}

\section{Participant $S$.}

S. was a right-handed, 32-year-old female residing in the Free State Province of South Africa who suffered a CVA in late 2002. At the start of this study, she had been living with aphasia for 6 years. S. completed 12 years of schooling, in which English and Sesotho were both used as media of instruction. She obtained a teaching diploma from a teachers' training college at age 21. Pre-morbidly she was employed as a primary-level Sesotho teacher. She reported that before her stroke she was able to speak English very well. Further, she had some command of Afrikaans, Xhosa, and Zulu. She commenced fortnightly speech-language therapy (provided by the lead author) in April of 2007 (about 13 months before this study started).

S. suffered a left-sided CVA and presented with a mild expressive aphasia. As she recovered from the initial effects of the stroke, her symptoms changed. At the time of the 
Archer, B., Müller, N. and Penn, C. (2016). Facilitation effects of cueing techniques in two Sesotho speakers with anomia. Speech, Language and Hearing, 19, 140-153.

study, her language output was consistent with a fluent aphasia. As in T.'s case, no imaging assessments of the locus of her neural lesion were undertaken. However, her symptoms (language disorders, decreased processing speed) were consistent with damage confined to cerebral regions.

S.'s score of 10/60 on a Sesotho-adapted version of the Boston Naming Test (Kaplan et al., 1983) suggested a lexical retrieval deficit. Her spontaneous speech also displayed behavioral signs often found in people with anomia. In general, her verbal output was characterized by frequent pauses; one speech sample of 50 utterances featured an average of two anomic moments per clause. During many utterances, S. would opt-out of producing problematic items, express frustration, and state that she could not remember, or did not know the relevant item. Paraphasias, predominantly of the semantic type, were also common. S. displayed insight into her word-finding deficit and often attempted to correct paraphasias she produced during speaking turns. During anomic incidents, S. sometimes employed meaningless filler material ('ummm...') while searching for the target word. Soon after her CVA, she developed the habit of circumlocuting in response to anomic moments. In the following example, she was trying to name a loaf of bread:

1) ummm...bona...bona...
class14 absolute pronoun verb+present tense marker

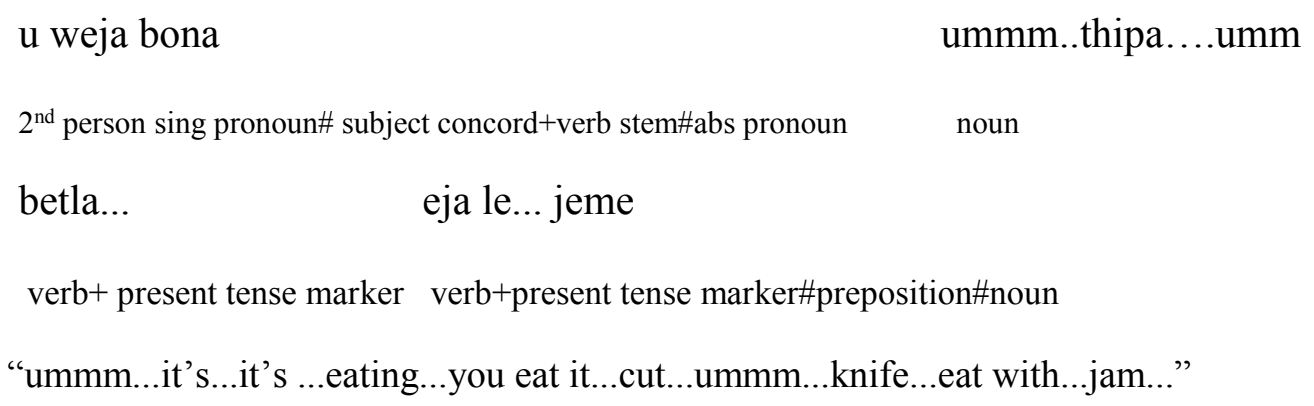

As can be seen from Table 4, S. presented with a more severe language impairment than $\mathrm{T}$. Though the Aphasia Quotient obtained by S. during formal testing was consistent with a 
Archer, B., Müller, N. and Penn, C. (2016). Facilitation effects of cueing techniques in two Sesotho speakers with anomia. Speech, Language and Hearing, 19, 140-153.

diagnosis of anomic aphasia, her score fell near the lower limits of this category. Her impairments in reading, repetition spelling, spoken word-picture matching, and written word-picture matching all appeared to be mild to moderate.

Table 4: Test scores for participant $S$.

\begin{tabular}{|l|l|}
\hline PALPA & \\
\hline Subtest & Score \\
\hline 8. Repetition: Nonwords & $21 / 30$ \\
\hline 8. Repetition: Nonwords reading & $25 / 30$ \\
\hline $\begin{array}{l}\text { 9. Repetition: Imageability and Frequency, high } \\
\text { imageability words only }\end{array}$ & $35 / 40$ \\
\hline 36. Oral Reading: Nonwords & $19 / 24$ \\
\hline 45. Spelling to dictation: Nonwords & $20 / 24$ \\
\hline 47. Spoken Word-Picture Matching & $27 / 40$ \\
\hline 48. Written word- picture matching & $31 / 40$ \\
\hline 53.1 Spoken Picture Naming & $5 / 40$ \\
\hline 53.2 Written Naming & $25 / 40$ \\
\hline 53.3 Oral reading & $38 / 40$ \\
\hline 53.4 Repetition & $38 / 40$ \\
\hline 53.5 Written spelling & $34 / 40$ \\
\hline $\begin{array}{l}\text { 54. Picture naming. } \\
\text { High frequency }\end{array}$ & $4 / 20$ \\
Medium frequency & $2 / 20$ \\
\hline Low frequency & $1 / 20$ \\
\hline & \\
\hline WAB & \\
\hline Subtest & Score \\
\hline Spontaneous Speech: Functional Content & 3 \\
\hline Spontaneous Speech: Fluency & 2 \\
\hline Spontaneous Speech Total & 5 \\
\hline Comprehension: yes/no questions. & 50 \\
\hline Comprehension: auditory word recognition & 50 \\
\hline Comprehension: sequential commands & 60 \\
\hline Comprehension Total: (scores divided by 20) & 3 \\
\hline Naming: Object Naming & 1 \\
\hline Naming: Word Fluency & 4 \\
\hline Naming: Sentence Completion & 1 \\
\hline Naming: Responsive Speech & 32 \\
\hline Naming Total: & \\
\hline Repetition: & 2 \\
\hline Aphasia Quotient (AQ): & \\
\hline
\end{tabular}


Archer, B., Müller, N. and Penn, C. (2016). Facilitation effects of cueing techniques in two Sesotho speakers with anomia. Speech, Language and Hearing, 19, 140-153.

In keeping with a variety of other clinical examinations of cueing therapy (DeDe et al., 2003; Rose and Douglas, 2008) custom word lists were developed for use in this study. If researchers elect to use a single word list in studies where two conditions are compared, confounds unrelated to the variable under consideration may arise. For example, accuracy scores obtained during the last condition may appear elevated simply because during the preceding conditions the participants were repeatedly exposed to stimuli (after Goodwin, 2009). To avoid sequence effects, before the study commenced, two word lists were developed.

Since our objective was not to assess how well each cue type helped participants regain the ability to name common items, but rather to compare one cue type to another, we felt it unnecessary to remove items the participants could name at the start of the study (known items) from the word lists. Many single case studies in the aphasiology literature (such as Laganaro et al. (2006), for example) include known words in the study stimuli. Moreover, our study design follows the suggestions provided by Kratochwill et al.'s (2010) guidelines for single case studies in that it compares baseline performance to performance under the experimental condition of interest (in this case, the two types of cues). The presence of known items was not seen as a factor which could adversely affect analysis and resultant conclusions.

The vocabulary list provided in Mokoena (1998) (a list of common words) was used as the basis for the word lists. Two initial lists consisting of 200 words each were constructed. Several criteria for minimizing the effects of extraneous variables related to the list were suggested by previous research:

(1) We attempted to balance the word lists for picturability (the degree to which a word can be represented by a picture) and name agreement so as to minimize the risk of prejudicing one condition over the other (after Goodglass et al., 1969). Full color, high- 
Archer, B., Müller, N. and Penn, C. (2016). Facilitation effects of cueing techniques in two Sesotho speakers with anomia. Speech, Language and Hearing, 19, 140-153.

resolution $177.8 \mathrm{~mm}$ by $215.9 \mathrm{~mm}$ (double standard postcard size) photographs of the words were sourced from online catalogs or from photographs taken solely for the purposes of this study using a digital camera. All pictures were pilot tested on 10 unimpaired Sesotho speakers from the Northern Free State. If a picture had high name agreement (all 10 of the speakers provided the target label for the picture), the word and picture were included in the study. This process ensured that the items featured on both lists had similar picturability and a high degree of name agreement.

(2) Some controversy exists concerning how words are stored in the mental lexicon, with some authors arguing that all words are stored as indivisible atomic units, while others believe the constituent morphemes of multi-morphemic words are stored individually (Kess, 1992). These positions have implications for the relative ease with which words are processed. In order to ensure that all the words used in this study were equal in terms of processing load, all words appearing on both lists consisted of a noun-class prefix and monomorphemic root.

(3) The word had to belong to the syntactic class 'noun' so as to avoid any potential effects related to syntactic class membership (after Bird et al., 2000).

(4) Not all nouns in Sesotho conform to the noun-class prefix patterns described by Demuth (2000). Only nouns that followed the common noun-class prefix patterns were included as stimuli.

(5) Borrowed words had to demonstrate evidence of assimilation, i.e. conform to accepted patterns of Sesotho phonology and phonotactics as defined by Doke and Mofokeng (1967). Under this criterion, borrowed items were not excluded since in any language a large proportion of common words may be borrowed from other languages (Campbell, 2013). (6) Most studies of word retrieval attempt to avoid effects related to frequency by selecting items that all have similar frequencies of usage. A corpus, usually based on a large amount of 
Archer, B., Müller, N. and Penn, C. (2016). Facilitation effects of cueing techniques in two Sesotho speakers with anomia. Speech, Language and Hearing, 19, 140-153.

written language, is typically consulted. Currently, no large corpus of written Sesotho materials exists. All of the words used in this study were common nouns taken from Mokoena (1998), a novice learner's guide to Sesotho. Moreover, the word had to be attested to as a word existing in the dialect of Sesotho spoken in the surrounding community, by at least 10 speakers who worked at the hospital at which T. and S. were receiving therapy These informants were asked to assess the word lists and to identify any words that they did not regard as common everyday lexical items. If a word was identified as being uncommon by 1 or more of the speakers, it was removed from the study.

(7) In the context of anomia studies, previous research suggests that some categories of words may be harder to produce than others; for example, some people with anomia tend to name inanimate objects with greater ease than animate things (Bird et al., 2000). In order to avoid prejudicing any one list (and facilitation condition) over another, the researcher attempted to balance semantic categories across word lists. All words belonging to a given semantic category (e.g. animals) were divided into two groups; if the category contained an odd number of items, one randomly selected item was dropped.

By applying these criteria, we reduced the size of each list from 200 items to 144 items. Each facilitation condition was assigned a 144-item word list; the association between each facilitation condition and its word list lasted throughout the study. (The word lists are available at Supplementary Materials - Word Lists.)

\section{Study design}

We compared the facilitatory effects of two techniques: initial phoneme cueing and uninflected root-based cueing (RBC). We chose to use terminology revolving around prefixes and roots, namely prefix-based cueing (PBC) and RBC since Sesotho morphology is universally described in these terms. To illustrate, when cueing a Sesotho speaker for the 
Archer, B., Müller, N. and Penn, C. (2016). Facilitation effects of cueing techniques in two Sesotho speakers with anomia. Speech, Language and Hearing, 19, 140-153.

word lehapu 'watermelon', an initial phoneme cue or prefix-based cue would consist of the first phoneme of the inflected (prefix+stem) word or /l-/. A root-based cue would consist of the first phoneme of the uninflected root or a /-h-/.

The study proceeded in two phases. During the first phase (baseline), confrontation naming probes were used to score each client's ability to name the items on the two 144-item lists. Four probes were administered, yielding four pre-facilitation data points per participant per condition. The 144 items assigned to each facilitation condition were presented in a random order.

The second phase (facilitation) of the study then commenced. To further protect against sequence effects, a random condition order was selected for participant T., and reversed for participant S. For participant T., PBC was followed by RBC, while for S. the opposite order was used. Under each condition, the relevant condition-specific word list was cycled through eight times. Eight cycles were thought to be sufficient in terms of yielding usable data concerning growth in naming abilities (after Allison and Gorman, 1993), yet tolerable to participants who volunteered for this study.

During the facilitation phase, cues based on the facilitation condition were provided to the participants. The order of items within the word lists was randomized. The accuracy of the names produced by the participants during these eight cycles was recorded, yielding eight data points per participant per condition. The conditions were sequenced serially (e.g. in the case of T., all eight PBC cycles occurred before all eight RBC cycles).

Participant T. required 24 45-minute sessions (spread over the course of 4 months) to complete eight cycles under both facilitation conditions. Participant S. required 35 45-minute sessions, also spread over the course of 4 months, to complete the same number of cycles under both facilitation conditions. 
Archer, B., Müller, N. and Penn, C. (2016). Facilitation effects of cueing techniques in two Sesotho speakers with anomia. Speech, Language and Hearing, 19, 140-153.

\section{Facilitation and data recording protocol}

In order to ensure that participants were exposed to each cue type the same number of times, the following protocol was used for cue presentation across conditions:

(1) Photographs were randomly sequenced and presented one at a time.

(2) The participant was instructed not to name the photograph until he/she had been given the cue.

(3) The participant was shown the photograph.

(4) The relevant cue was provided.

(5) The participant was asked to name the picture.

(6) If the participant spontaneously attempted to selfcorrect a response, the correct or fifth (whichever came first) production was coded (i.e. self-corrected responses beyond the fifth trial were not coded).

(7) If the participant did not make any attempt to name the picture within 30 seconds, the item was scored as a zero production.

(8) The researchers and participant took a short break after recording the participants' answers before moving onto the next item.

(9) Participant responses were coded according to the following scheme: an immediate or delayed (less than 30 seconds) production which was phonemically and semantically identical to the target was coded as an accurate response. All other responses were coded as errors.

(10) The lead researcher and interpreter conferred before a response was coded as correct or incorrect. Given the simple and objective criterion used to discriminate between these categories (see 9. above), disagreements were very rare (fewer than $1 \%$ of the 3200 confrontation naming events which occurred during this study were linked to an interpreterresearcher mismatch concerning the correctness of responses). Further, the interpreter was 
Archer, B., Müller, N. and Penn, C. (2016). Facilitation effects of cueing techniques in two Sesotho speakers with anomia. Speech, Language and Hearing, 19, 140-153.

not informed that PBCs (as versions of initial phoneme cues) could be considered wellestablished within the literature, and that RBCs were a newer variant technique under investigation (such information was withheld from her in order to reduce prejudicing either cueing approach during data recording). Division of participant responses recorded during the facilitation phase into more refined categories (semantic vs. phonemic paraphasias, for example) was not attempted.

(11) Coding was conducted via writing, in such a way that the participants were usually not privy to the scores assigned by the researcher and the interpreter. In the event that the researcher and interpreter disagreed that a response was right or wrong (which happened for less than $1 \%$ of the confrontation naming events in this study), the researcher and interpreter had a brief discussion. These discussions were so rare that their effect on participant performance was assumed to be negligible.

\section{Statistical analysis and results}

\section{Data}

Figsures 1 and 2 represent the data which inform our statistical analysis. In both figures, the first four data points reflect participant naming accuracy during the baseline phases (i.e. no cues were provided to participants; they were simply asked to name the 144 items on each word list across four cycles, and the correctness/ incorrectness of their response was recorded). The subsequent eight data points represent participant responses under the facilitation conditions (i.e. either RBC or PBC cues were provided to participants as per the protocol set out in Section 'Facilitation and data recording protocol'; their attempts to name the 144 items on each word list across eight cycles were recorded as 'correct/incorrect'). It should be noted that the data pertaining to the first four data points are thus different from that pertaining to the last eight data points, since such data were gathered under conditions 
Archer, B., Müller, N. and Penn, C. (2016). Facilitation effects of cueing techniques in two Sesotho speakers with anomia. Speech, Language and Hearing, 19, 140-153.

characterized by two different researcher inputs (for the first four data points, the researcher asked the participants to name pictures without providing any cues, while for the last eight data points the researcher provided cues).

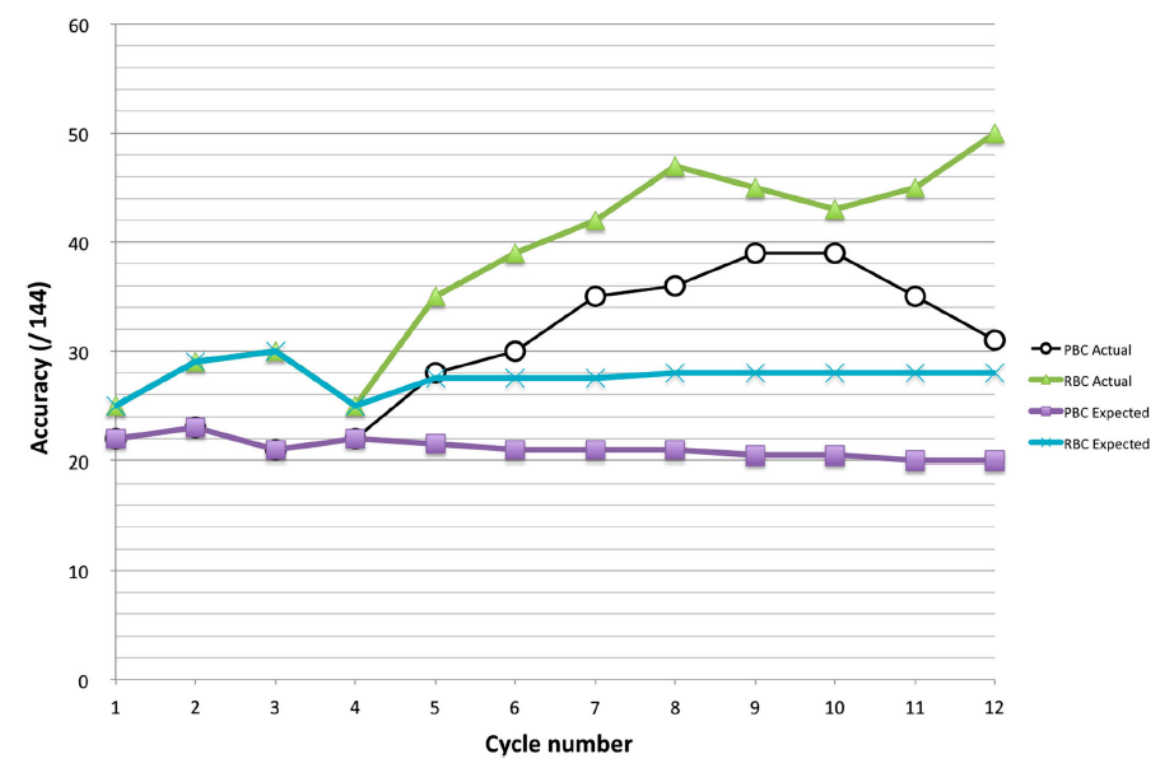

Figure 1: Baseline and facilitation scores obtained by T. under both cueing conditions.

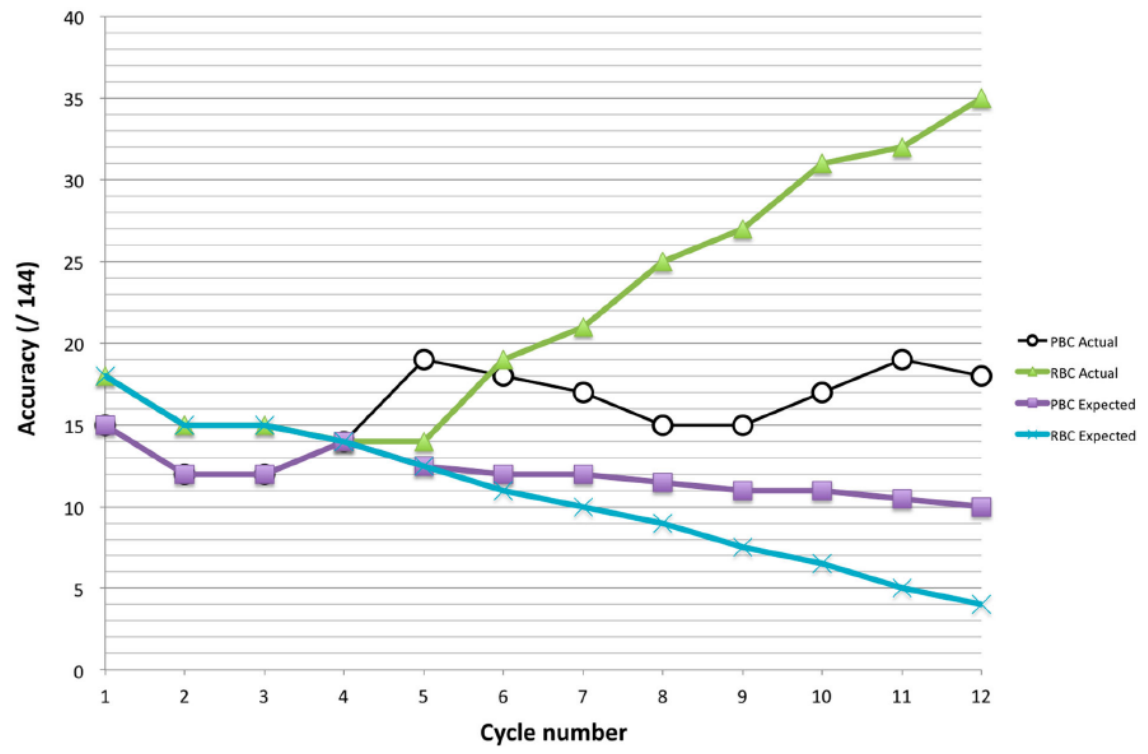

Figure 2: Baseline and facilitation scores obtained by S. under both cueing conditions. 
Archer, B., Müller, N. and Penn, C. (2016). Facilitation effects of cueing techniques in two Sesotho speakers with anomia. Speech, Language and Hearing, 19, 140-153.

\section{Effect size}

Many researchers believe that effect size measures can be used to assess the impacts of intervention in small $\mathrm{n}$ and single case studies (ASHA, 2004; Beeson and Robey, 2006; Ferguson, 2009; Parker and Brossart, 2003). In studies where the impact of a relevant condition on behavior is tracked over time (as it was in this study during the baseline and facilitation phases), researchers should attempt to differentiate between the influence of the condition and the influence of the participant's residual, pre-study abilities on outcome measures. Accordingly, Parker and Brossart (2003) argue in favor of using regressionbased methods to determine effect size in studies where data are gathered over time. The Allison's mean-plus-trend (Allison-MT) procedure yields a regression-derived statistic which is designed to minimize the effects of both pre-existing client abilities and the random fluctuations observed in any natural system (Parker and Brossart, 2003).

In order to determine an Allison-MT statistic, the first four data points (labeled 'baseline' on the figures) were used to extrapolate the 'expected scores' line. This line is thought to depict natural tendencies in the participants' naming abilities in the absence of any experimental effect (after Allison and Gorman, 1993). The 'actual scores' line is derived from the facilitation phase data points and is thought to depict the effect of the relevant variable (in this case, the given facilitation technique) on participant performance. The values of these expected data points are subtracted from the data points actually obtained during the study. A multiple linear regression statistic (R2) is then calculated using this detrended data (Allison and Gorman, 1993). Since three variables are featured in this model, R2 should be adjusted (Hinton, 2004).

The effect sizes for each participant and facilitation condition are given in Table 5 (critical values calculated at $\mathrm{P}=0.05$ level) (after Hinton, 2004). A post hoc $F$ test was conducted for each of the effect sizes. For this study, the F-test results support the view that a 
Archer, B., Müller, N. and Penn, C. (2016). Facilitation effects of cueing techniques in two Sesotho speakers with anomia. Speech, Language and Hearing, 19, 140-153.

significant correlational relationship exists between the response variable (in this case, naming accuracy) and the predictors (in this case, session number and presence/absence of cueing) (Field, 2013).

Table 5: Effect sizes, for both participants, under both facilitation conditions.

\begin{tabular}{|l|l|l|}
\hline & PBC & RBS \\
\hline \multirow{2}{*}{ Participant T } & $\mathrm{R}^{2}=0.55, \mathrm{~F}(3,8)=5.5$ & $\begin{array}{l}\mathrm{R}^{2}=0.78, \mathrm{~F}(3,8)=15.9 \\
\text { (Critical value: } 4.26)\end{array}$ \\
& (Critical value: 4.26$)$ & $\begin{array}{l}\mathrm{R}^{2}=0.78, \mathrm{~F}(3,8)=15.9 \\
\text { (Critical value: } 4.26)\end{array}$ \\
\hline \multirow{2}{*}{ Participant $\mathrm{S}$} & $\mathrm{R}^{2}=0.65, \mathrm{~F}(3,8)=8.3$ & \\
& (Critical value: 4.26$)$ & \multicolumn{2}{|l}{} \\
\hline
\end{tabular}

While both techniques produced effect sizes that exceed Cohen's guideline for designating an effect as large (0.5) (Cohen, 1977), differences between the effect sizes associated with each cueing type can be discerned, with RBC appearing superior in the context of this study.

\section{Matched pair testing}

To provide support for the claim that PBCs are more effective at facilitating naming performance than RBCs, we conducted a McNemar's test. To compare PBCs to RBCs, we paired the PBC and RBC word lists (each item on the PBC word list was paired with an item on the RBC word list; words in a given semantic category on the PBC list were paired with words in the same semantic category on the RBC list). Data drawn from each participant's final facilitation session (which detailed the words on the PBC list each participant named correctly as well as the words on the RBC word list each participant named correctly). These data appear in Tables 6 and 7, and were used to populate $2 \times 2$ contingency tables. For participant T., $\chi 2=4(1,12), \mathrm{P}=0.0045$. For participant $\mathrm{S} ., \chi^{2}=5.93(1,12), \mathrm{P}=0.00685$. In 
Archer, B., Müller, N. and Penn, C. (2016). Facilitation effects of cueing techniques in two Sesotho speakers with anomia. Speech, Language and Hearing, 19, 140-153.

both instances, the analysis indicates a statistically significant difference exists between the $\mathrm{PBC}$ and RBC scores.

Table 6: Matched pair performance for participant $\mathrm{T}$.

\begin{tabular}{|l|l|}
\hline Pair description & Number \\
\hline PBC and RBC item produced correctly & 18 \\
\hline Only PBC item produced correctly & 13 \\
\hline Only RBC item produced correctly & 32 \\
\hline Neither PBC nor RBC item produced correctly & 81 \\
\hline
\end{tabular}

Table 7: Matched pair performance for participant S.

\begin{tabular}{|l|l|}
\hline Pair description & Number \\
\hline PBC and RBC item produced correctly & 5 \\
\hline Only PBC item produced correctly & 13 \\
\hline Only RBC item produced correctly & 30 \\
\hline Neither PBC nor RBC item produced correctly & 96 \\
\hline
\end{tabular}

\section{Discussion}

The results of this comparative study suggest that $\mathrm{RBC}$ is the more effective facilitation technique for Sesotho speakers with anomia. This finding provides further support for Penn's (2012) contention that if techniques oriented to the unique parameters of Sesotho are included in therapeutic programs designed for Sesotho speakers, intervention will yield greater benefits than if techniques developed in a radically different language context are employed. Since Sesotho is closely related to other languages spoken in South Africa (such as Setswana and Sepedi) (Lewis et al., 2013), the current research could certainly serve as a starting point for investigating the use of RBCs in most of South Africa's Bantu languages. The methods and principles discussed would be applicable to such future studies. 
Archer, B., Müller, N. and Penn, C. (2016). Facilitation effects of cueing techniques in two Sesotho speakers with anomia. Speech, Language and Hearing, 19, 140-153.

One noteworthy finding in this study is the facilitatory effect noted for both cueing conditions; though RBCs appeared relatively more effective at improving naming performance, $\mathrm{PBCs}$ were also linked to definite positive changes in naming, as evidenced by expected-actual line differences. A possible psycholinguistic explanation for improved naming relies on the concept of activation summation (Lambon Ralph et al., 1999). For both participants, a certain amount of residual activation cascaded through the network during naming tasks. Cues provided by an interlocutor provide additional activation which is thought to interact with that already present in the client's network (Lambon Ralph et al., 1999). The sum of the residual and external activation appear (in many cases) sufficient to improve naming performance (Avila et al., 2001).

Repeated practice, with provision of cues, appears to increase naming ability (Wisenburn and Mahoney, 2009). Such improvement is consistent with the ILN model. Connection weights tend to increase every time a word is retrieved (Dell et al., 2014); presumably, successful therapy makes the overall network more efficient because it improves connections such that they transmit adequate activation for an adequate period.

A model-based explanation for differences under the two facilitation conditions makes recourse to the concept of feedback. Most nouns in Sesotho (and all the nouns used in this study) share 14 noun-class prefixes which in turn have five initial phonemes $(/ \mathrm{m} /, / \mathrm{b} /, / 1 /$, /s/, /d/). The nodes associated with these phonemes at the phonological level are presumably connected to a large number of lemmas, since they appear in many Sesotho words. By contrast, the set of phonemes which appear in the initial position of uninflected noun roots (for example, /h/ in *hapu the uninflected root of lehapu) is larger. Instead of being connected to a sizable percentage of all nouns (as is the case for each prefix initial phoneme), the initial phonemes of uninflected roots are connected to a much smaller number of nouns. These 
Archer, B., Müller, N. and Penn, C. (2016). Facilitation effects of cueing techniques in two Sesotho speakers with anomia. Speech, Language and Hearing, 19, 140-153.

phoneme nodes may be located in a region of the network characterized by a relatively small number of connections.

During the PBC condition, the cue provided activation at the phoneme node associated with each prefix. Since these nodes are linked to a large number of lemmas, activation may have fed back to the lemma level bringing a large number of lemmas online. During the RBC condition, the cue provided activation to a phoneme node that was linked to a much smaller number of lemmas. Activation fed back to the lemma level would thus have brought a much smaller number of lemmas online. In sum, because of varying numbers of phoneme node-lemma connections and feedback, PBCs may have led to more widespread activation than RBCs.

Since both participants have aphasia, random activity (noise) may impair function in the lexical network. Due to the interface between phonology and morphology in Sesotho, one cueing technique (PBC) appeared to lead to excess activation, which would have exacerbated the effects of noise. PBC brought so many lemmas online that the participants' ability to correctly select the appropriate label was impaired, while RBCs furnished the participants with a much smaller number of choices.

Differences in performance between participants may be attributed to levels of general linguistic capacities. Participant T. displayed a clinical picture similar to prototypical anomic aphasia. His overall communicative ability and linguistic processing abilities appeared to be relatively well-preserved. Aside from frequent word-finding difficulties, his speech was largely fluent and he was able to complete most linguistic tasks aside from confrontation naming.

Since T. displayed relative strength during many linguistic processing tasks, it might be reasonably argued that the editing elements operating within his wordretrieval system are relatively intact. During picture naming tasks, a PBC may have provided excess activation, 
Archer, B., Müller, N. and Penn, C. (2016). Facilitation effects of cueing techniques in two Sesotho speakers with anomia. Speech, Language and Hearing, 19, 140-153.

and the editing function may have been robust enough to avoid selecting erroneous lemmas. Though the network was often too dysfunctional to overcome this excess activation, its editing power was sufficient to reject incorrect choices. RBCs provided less widespread activation, which interacted with the system's residual activation, allowing T. to complete naming tasks with greater accuracy.

Participant S., on the other hand, displayed more general expressive symptoms. The scores she obtained on formal measures of linguistic processing were noticeably lower than T.'s. Her speech was also much slower, more halting, and characterized by frequent pauses and semantic paraphasias. Again, the model provides a scaffold on which to construct an explanation; editing functions within her lexical network were probably not effective enough to guard against erroneous choices, giving rise to the noted semantic paraphasias. In her case, her lexical network (in the absence of an optimal sifting mechanism) may simply have randomly selected one of the active lemmas for production during naming tasks. PBCs provided a much larger pool of candidates from which to choose, leading to many more incorrect productions. To summarize model-guided interpretations of these results, it appears as though both cue types were effective at increasing naming performance in both participants since both techniques provided some additional activation. Because of the unique interplay between phonology and morphology in Sesotho (i.e. a small set of phonemes are produced in the initial position of most normally inflected nouns), PBCs provided too much activation. The interaction between such cue-related activation and random activity (present because of neural damage) overwhelmed both participants' networks. RBCs may have been superior since they provided sufficient activation, focused in a more limited area.

One limitation of this study concerns the way in which the word lists were balanced. While the community attestation approach we adopted did help to produce word lists that were comparable in terms of picturability, our efforts to ensure equivalence for other word 
Archer, B., Müller, N. and Penn, C. (2016). Facilitation effects of cueing techniques in two Sesotho speakers with anomia. Speech, Language and Hearing, 19, 140-153.

characteristics were hampered by the fact that no large spoken or written Sesotho corpus exists. When studying English speakers, researchers can use databases such as that referenced in Coltheart (1981) to produce lists that are closely matched. In this study, because no such Sesothobased resources exist, we were unable to control for imageability.

Moreover, this study cannot be viewed as a fullfledged, comprehensive investigation of the therapeutic value of RBCs; we simply sought to assess which of two different cueing techniques would improve naming abilities on two very specific, circumscribed lists of nouns. In this experiment, RBCs proved to be the superior technique. True treatment studies feature a number of elements (a concern with generalization to untreated items, the use of uncued probes throughout the course of the study to gauge growth in naming abilities, provision of cues after the participant has attempted to produce an item, feedback provided to the participants concerning the accuracy of their productions) which were absent from this study. Further research into how well the results obtained generalize to non-treated lexical items, or a comparison to words targeted in a placebo condition, would provide greater support for the inclusion of RBCs within a larger therapeutic endeavor. Further, no formal attempt was made to determine whether or not either technique was linked to decreased anomic episodes in connected conversation. Clearly, the results presented here need to be interpreted in light of these limitations. Further research is needed before the true utility of RBCs can be accurately gauged. Nonetheless, the results of this study are encouraging, and suggest that future studies are warranted.

In conclusion, this study represents a first step towards the development of a contextual aphasiology for speakers of Bantu language in South Africa. As SLPs become increasingly aware of the complexities of service delivery in a world with many languages, more and more authors are striving to ensure that therapy closely aligns with the lived experience of clients. While previous studies conducted in Englishspeaking environments can 
Archer, B., Müller, N. and Penn, C. (2016). Facilitation effects of cueing techniques in two Sesotho speakers with anomia. Speech, Language and Hearing, 19, 140-153.

provide inspiration, we suggest that clinicians need to consider a range of other factors.

Understanding how word retrieval occurs in unimpaired speakers coupled with an appreciation of the linguistics parameters of the language(s) spoken by a client can help therapists develop more effective and efficient interventions.

\section{Disclaimer statements}

Contributor Ms Mmathakgodi Rens was employed as an interpreter for this project.

Funding None.

Conflicts of interest None.

Ethics approval Ethical oversight provided by the Humanities Ethics Committee (nonmedical) of the University of the Witwatersrand.

\section{Supplemental data}

Supplemental data for this article can be accessed at http://dx.doi.org/10.1080/2050571X.2016.1155817.

\section{References}

Abel, S., Schultz, A., Radermacher, I.,Willmes, K., Huber,W. 2005. Decreasing and increasing cues in naming therapy for aphasia. Aphasiology, 19(9): 831-848.

Allison, D., Gorman, B. 1993. Calculating effect sizes for metaanalysis: the case of the single case. Behaviour Research and Therapy, 31(6): 621-631.

American Speech and Hearing Association (ASHA) 2004. Technical report on evidencebased practise in communication disorders: an introduction. Rockland, Maryland: ASHA. Retrieved from http ://www.asha.org/policy/TR2004-00001/ 
Archer, B., Müller, N. and Penn, C. (2016). Facilitation effects of cueing techniques in two Sesotho speakers with anomia. Speech, Language and Hearing, 19, 140-153.

Archer, B. 2010. Lesions, lemmas and lehapu: anomia in two Sesotho-English bilingual speakers. Master's Thesis, University of the Witwatersrand, Johannesburg.

Avila, C., Lambon Ralph, M., Parcet, M., Geffner, D., Gonzalez- Darder, J. 2001. Implicit word cues facilitate impaired naming performance: evidence from a case of anomia. Brain and Language, 79(2): 85-200.

Beeson, P.M., Robey, R.R. 2006. Evaluating single-subject treatment research: lessons learned from the aphasia literature. Neuropsychology Review, 16(4): 161-169.

Beveridge, T., Bak, M. 2011. The language of aphasia research: bias and diversity. Aphasiology, 25(12): 1451-1468.

Bird, H., Howard, D., Franklin, S. 2000. Why is a verb like an inanimate object? Grammatical category and semantic category deficits. Brain and Language, 72(3): 246309.

Bruce, C., Howard, D. 1987. Computer-generated phonemic cues: an effective aid for naming in aphasia. British Journal of Disorders of Communication, 22(3): 191-201.

Campbell, L. 2013. Historical linguistics. Edinburgh: Edinburgh University Press.

Cohen, J. 1977. Statistical power analysis for the behavioral sciences. New York: Lawrence Erlbaum Associates, Inc.

Coltheart, M. 1981. The MRC psycholinguistic database. The Quarterly Journal of Experimental Psychology, 33(4): 497-505.

Conroy, P., Sage, K., Lambon Ralph, M. 2009. The effects of decreasing and increasing cue therapy on improving naming speed and accuracy for verbs and nouns in aphasia. Aphasiology, 23(6): 707-730.

Costa, A., Caramazza, A., Sebastian-Galles, N. 2000. The cognate facilitation effect: implications for models of lexical access. Journal of Experimental Psychology: Learning, Memory, and Cognition, 26(5): 1283-1296. 
Archer, B., Müller, N. and Penn, C. (2016). Facilitation effects of cueing techniques in two Sesotho speakers with anomia. Speech, Language and Hearing, 19, 140-153.

DeDe, G., Parris, D., Waters, G. 2003. Teaching self-cues: a facilitation approach for verbal naming. Aphasiology, 17(5): 465-480. Dell, G. 1986. A spreading activation theory of retrieval in sentence production. Psychological Review, 93(3): 283-321.

Dell, G., Reich, P. 1981. Stages in sentence production: an analysis of speech error data. Journal of Verbal Learning and Verbal Behavior, 20(6): 611-629.

Dell, G., Schwartz, M., Martin, N., Saffran, E., Gagnon, D. 1997. Lexical access in aphasic and nonaphasic speakers. Psychological Review, 104(4): 801-838.

Dell, G., Chang, F., Griffin, Z. 1999. Connectionist models of language production: lexical access and grammatical encoding. Cognitive Science, 23(4): 517-542.

Dell, G., Nozari, N., Oppenheim, G. 2014.Word production: behavioral and computational considerations. In: Goldrick, M., Ferreira, V., Miozzo, M. (eds.), The Oxford handbook of language production, pp. 88-104. Oxford: Oxford University Press.

Demuth, K. 2000. Bantu noun class systems: loanword and acquisition evidence of semantic productivity. In Senft, G. (ed.), Systems of nominal classification, pp. 270-292. Cambridge, UK: Cambridge University Press.

Doke, C., Mofokeng, S. 1967. Textbook of southern Sotho grammar. Longmans: Cape Town. Ferguson, C.J. 2009. An effect size primer: a guide for clinicians and researchers.

Professional Psychology: Research and Practice, 40(5): 532-541.

Field, A. 2013. Discovering statistics using IBM SPSS. London: Sage.

Goodglass, H., Hyde, M.R., Blumstein, S. 1969. Frequency, picturability and availability of nouns in aphasia. Cortex, 5(2): 104-119.

Goodwin, C. 2009. Research in psychology: methods and design. Philadelphia: John Wiley \& Sons. Greenwood, A., Grassly, J., Hickin, J., Best, W. 2010. Phonological and orthographic cueing therapy: a case of generalised improvement. Aphasiology, 24(9): 991-1016. 
Archer, B., Müller, N. and Penn, C. (2016). Facilitation effects of cueing techniques in two Sesotho speakers with anomia. Speech, Language and Hearing, 19, 140-153.

Grodzinsky, Y. 2000. The neurology of syntax: language use without Broca's area. Behavioral and Brain Sciences, 23(01): 1-21.

Hinton, P. 2004. Statistics explained: a guide for social science students. London: Routledge. Kaplan, E., Goodglass, H.,Weintraub, S. 1983. The Boston Naming Test. Philadelphia: Lea \& Febiger.

Kay, J., Lesser, R., Coltheart, M. 1992. PALPA: psycholinguistic assessments of language processing in aphasia. Oxford: Psychology Press.

Kendall, D., Pompon, R., Brookshire, C., Minkina, I., Bislick, L. 2013. An analysis of aphasic naming errors as an indicator of improved linguistic processing following phonomotor facilitation. American Journal of Speech-Language Pathology, 22(2): S240-S249.

Kertesz, A. 1982. Western Aphasia Battery test manual. San Antonio: Psychological Corp. Kess, J.F. 1992. Psycholinguistics: psychology, linguistics, and the study of natural language. Philadelphia: John Benjamins Publishing.

Kratochwill, T., Hitchcock, J., Horner, R., Levin, J., Odom, S., Rindskopf, D., Shadish, W. 2010. Single-case designs technical documentation. What Works Clearinghouse. Retrieved http ://files.eric.ed.gov/fulltext/ED510743.pdf (accessed January 2015).

Laganaro, M., Di Pietro, M., Schnider, A. 2006. Computerised treatment of anomia in acute aphasia: treatment intensity and training size. Neuropsychological Rehabilitation, 16(6): 630-640.

Lambon Ralph, M., Cipolotti, L., Patterson, K. 1999. Oral naming and oral reading: do they speak the same language?. Cognitive Neuropsychology, 16(2): 157-169.

Levelt, W. 1999. Models of word production. Trends in Cognitive Sciences, 3(6): 223-232. Levelt,W.,Meyer, A. 2000.Word for word: multiple lexical access in speech production. European Journal of Cognitive Psychology, 12(4): 433-452. 
Archer, B., Müller, N. and Penn, C. (2016). Facilitation effects of cueing techniques in two Sesotho speakers with anomia. Speech, Language and Hearing, 19, 140-153.

Levelt, W., Roelofs, A., Meyer, A. 1999. A theory of lexical access in speech production. Behavioral and Brain Science, 22(01): 1-75.

Lewis, M., Simons, G., Fennig, C. 2013. Sotho, Southern. Ethnologue: Languages of the World. Retrieved 1 September 2013. http://www.ethnologue.com/language/sot.

Martin, F. 1994. Introduction to audiology. Englewood Cliffs, New Jersey: Prentice Hall. Mokoena, A. 1998. Sesotho made easy. Pretoria: JL van Schaik.

Nettleton, J., Lesser, R. 1991. Therapy for naming difficulties in aphasia: application of a cognitive neuropsychological model. Journal of Neurolinguistics, 6(2): 139-157.

Paradis, M., Libben, G. 1987. The assessment of bilingual aphasia. Hillsdale: Lawrence Erlbaum Associates.

Parker, R.I., Brossart, D.F. 2003. Evaluating single-case research data: a comparison of seven statistical methods. Behavior Therapy, 34(2): 189-211.

Pascoe, M., Maphalala, Z., Ebrahim, A., Hime, D., Mdladla, B., Mohamed, N., Skinner, M. 2010. Children with speech difficulties: a survey of clinical practice in the Western Cape. South African Journal of Communication Disorders, 57(1): 66-76.

Penn, C. 2012. Toward cultural aphasiology: contextual models of service delivery in aphasiology. In: Gitterman, M., Goral, M. \& Obler, L. (eds.), Aspects of multilingual aphasia, pp. 292-306. Bristol: Multilingual Matters.

Penn, C., Archer, B. 2011. The facilitation of anomia in Sesotho: A case for parametric aphasiology. Clinical Linguistics \& Phonetics, 25(11-12): 1059-1065.

Penn,C., Beecham, R. 1992. Discourse therapy inmultilingual aphasia: a case study. Clinical Linguistics \& Phonetics, 6(1-2): 11-25.

Robertson, S., Thomson, F. 1986. Working with dysarthrics: a practical guide to therapy for dysarthria. New York: Winslow Press. 
Archer, B., Müller, N. and Penn, C. (2016). Facilitation effects of cueing techniques in two Sesotho speakers with anomia. Speech, Language and Hearing, 19, 140-153.

Rose, M., Douglas, J. 2008. Treating a semantic word production deficit in aphasia with verbal and gesture methods. Aphasiology, 22(1): 20-41.

Sejaphala, M. 2010. The morpheme "le" inNorthern Sotho: a linguistic analysis. Doctoral thesis, University of the North, Polokwane.

Wambaugh, J., Linebaugh, C., Doyle, P., Martinez, A., Kalinyak- Fliszar, M., Spencer, K. 2001. Effects of two cueing facilitations on lexical retrieval in aphasic speakers with different levels of deficit. Aphasiology, 15(10-11): 933-950.

Wilshire, C.E. 2008. Cognitive neuropsychological approaches to word production in aphasia: beyond boxes and arrows. Aphasiology, 22(10): 1019-1053.

Wisenburn, B., Mahoney, K. 2009. A meta-analysis of word-finding facilitations for aphasia. Aphasiology, 23(11): 1338-1352. 